\title{
Regional Differences in Postnatal Care Service Utilisation and Child Morbidity in Nigeria: Evidence from 2018 Nigeria Demographic and Health Survey (NDHS)
}

\author{
ENDURANCE UZOBO ${ }^{* *}$ and ABOLUWAJI D. AYINMORO² \\ ${ }^{1}$ Department of Sociology, Niger Delta University, Bayelsa State, Nigeria. \\ ${ }^{2}$ Department of Sociology, University of Ibadan, Oyo State, Nigeria.
}

\begin{abstract}
Modern Postnatal Care (PNC) Services in Nigeria is a vital tool for providing quality health for mothers and newborns. Nonetheless, many Nigeria regions are still struggling to achieve optimum utilisation of Postnatal Care Services due to variations in mothers' associated socio-economic factors based on their specific locations. This study aims at assessing regional socio-economic factors associated with Postnatal Care Services utilisation and its relationship with child morbidity in Nigeria. Data for this study was extracted from the Nigeria Demographic and Health Survey (NDHS) 2018 birth recoded file dataset, with a sample size of 30,713 women (aged 15-49). Data were analysed using descriptive statistics, Chi-Square Test, and logistic regression reporting the result in odds-ratios (OR). The primary predictor variable was the region, while others included the type of Postnatal Care Services utilised and various demographic variables of the respondents - age, education, type of residence, religion, and ethnicity. The average age of the respondents was $29.5 \pm 6.8$. The use of modern Postnatal Care Services ranged from South-West (20.3\%), South-South (10.9\%), SouthEast $(23.0 \%)$, North-Central $(22.0 \%)$, North-East $(13.0 \%)$ to North-West $(10.9 \%)$. The prevalence of child morbidity ranged from South-West $(8.5 \%)$, South-South (9.8\%), South-East (11.4\%), North-Central (15.3\%), North-East $(26.3 \%)$ to North-West $(28.7 \%)$. Child morbidity is significantly higher in the South-South $(\mathrm{OR}=1.46,95 \%$ Confidence Interval $[\mathrm{Cl}]=1.316$ $-1.611 ; p=0.01)$, South-East $(O R=1.50)$, North-Central $(O R=1.13)$, NorthEast $(\mathrm{OR}=2.31)$ and North-West $(\mathrm{OR}=1.35)$ compared to the South-West. The majority of women in Nigeria are not using modern PNC services. Regional variations in the use of PNC services and mothers' sociodemographic characteristics influence child morbidity in Nigeria. There should be region-specific sensitisation of women on the need for the benefit of modern health care for both antenatal care and postnatal care services.
\end{abstract}

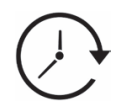

Article History

Received: 19 December 2020

Accepted: 15 February 2021

\section{Keywords}

Child Morbidity;

Healthcare;

Postnatal Care

Services;

Regions In Nigeria.

CONTACT Endurance Uzobo 1 enduzobo@gmail.com 9 Department of Sociology, Niger Delta University, Bayelsa State, Nigeria. 


\section{Introduction}

Due to the changes that are bound to occur during the period of postnatal care (0-6 months after birth) in the lives of mothers and their newborn babies, the World Health Organisation (WHO) has reiterated that the period is a critical phase in the lives of the mothers and the newborn babies. ${ }^{1}$ Following the critical nature of this period, the Nigeria Demographic and Health Survey (NDHS 2018) report has also shown that the continuous provisions of health care services during pregnancy and childbirth including after delivery are important for the survival and well-being of both the mothers and their infants. As the report succinctly puts it: "Ensuring access to a continuum of care for women during the antenatal, intrapartum, and postpartum periods is critical for maternal and newborn survival and is a priority of the Federal Ministry of Health". ${ }^{2}$

Despite the importance of providing quality health care services by skilled health care professionals during and immediately after childbirth to mothers and infants, the postnatal periods are usually neglected by most mothers due to sociocultural factors associated with new-borns. ${ }^{3-5}$ Meanwhile, studies have shown that mothers who attend health facilities during postnatal periods where skilled health professionals can identify, observe and manage any health challenge that may arise in the lives of the mothers and their newborn babies ${ }^{6-7}$ stand a chance of preventing the occurrence of body and mental damage ${ }^{8}$ as well as child morbidity and mortality than those who did not. ${ }^{9}$

Although there has been incredible progress in the global under-five mortality rate which had reduced from 93 deaths (in 1990) and 76 deaths (in 2000) to 39 deaths per 1,000 live births in 201810, the reduction in this rate is uneven across regions and income levels in the world. For example, while the death of children under-five has declined from 182 to 78 deaths per 1000 live births in sub-Saharan Africa between 1990 and 2018, Europe and Northern America recorded a decline from 14 to 6 deaths during the same period. ${ }^{10}$ This implies that the current mortality rate in sub-Saharan Africa is 13 times more than those in Europe and Northern America.

In Nigeria, it was reported that between 1990 and 2018 , the under-5 mortality rate has declined from 193 deaths to 132 deaths per 1,000 live births. ${ }^{2}$
It then means that the under-5 mortality rate as of 2018 is 3 times higher than that of the global estimates and 2 times higher than that of subSaharan Africa. While the trend in the deaths of children under-five seems to decline at the national level in Nigeria, the rates are not evenly distributed across all regions or geopolitical zones in the country. For example, the rates across the geopolitical zones as at 2018 ranged from 95 deaths per 1000 (North-Central), 134 deaths per 1000 (North-East), 184 deaths per 1000 (North-West), 25 deaths per 1000 (South-East), 73 deaths per 1000 (South-South) to 62 deaths per 1000 (South-West). ${ }^{2}$ Given that the rates of decline in under-five mortality are not evenly distributed across continents and regions, it is indicative that there are disparities in the rates of socio-economic development as well as people's attitudes towards prevention of child morbidity and mortality in the country.

While several studies on postnatal care have focused on the use, non-use and barriers to the use of modern health care services during this period, ${ }^{4-5}$ there is limited or little attention paid to the relationship between regional differences in postnatal care services and child morbidity which is a critical factor in under-five mortality. Take, for example, Olajubu et al. ${ }^{5}$ examined the predictors of postnatal care utilisation among women in a facilitybased study in Nigeria, it was found that age and education were strong predictors of postnatal care services utilisation.

Ugboanusi et al. ${ }^{4}$ on the other hand, studied factors affecting the utilisation of postnatal care services in Primary Health Care (PHC) facilities in urban and rural settlements in Kaduna (Nigeria), postnatal care service utilisation was lower in the rural areas than the urban centres and there were barriers of transportation, large babies and poor wealth quintiles to the use of PHC facilities. Rao et al. ${ }^{11}$ in their study in India pointed out that mothers of newborns have to bathe water with ashes within seven days after delivery. These practices may be good for the mothers and their newborns from their cultural viewpoints, but the health implications could be more deleterious than its merits in modern health perspectives.

Meanwhile, Defar et al. ${ }^{12}$ have argued that maternal and child health $(\mathrm{MCH})$ care utilisation often varies 
with geographic location. As such, there is a need for an empirical study analysing regional differences in the use of postnatal care services and child morbidity using the recent data from the 2018 NDHS in Nigeria. This is urgently needed to explore the incidences of child morbidity in the country for necessary health programmes and interventions as well as to achieve target 3.2 of the Sustainable Development Goals, which seeks to end preventable deaths of newborns and children under 5 years, and reduce mortality rate to at least as low as 12 and 25 per 1000 live births. ${ }^{13}$
On this note this study was designed to achieve four objectives namely; (i) investigate regional variations in postnatal care practices among women of reproductive age in Nigeria, (ii) explore regional differences in the patterns of postnatal care utilization among women of reproductive age in Nigeria, (iii) describe regional differences in sociocultural determinants of postnatal care practices among women of reproductive age in Nigeria, and (iv) examine the relationship between postnatal care service utilization and child morbidity in Nigeria.

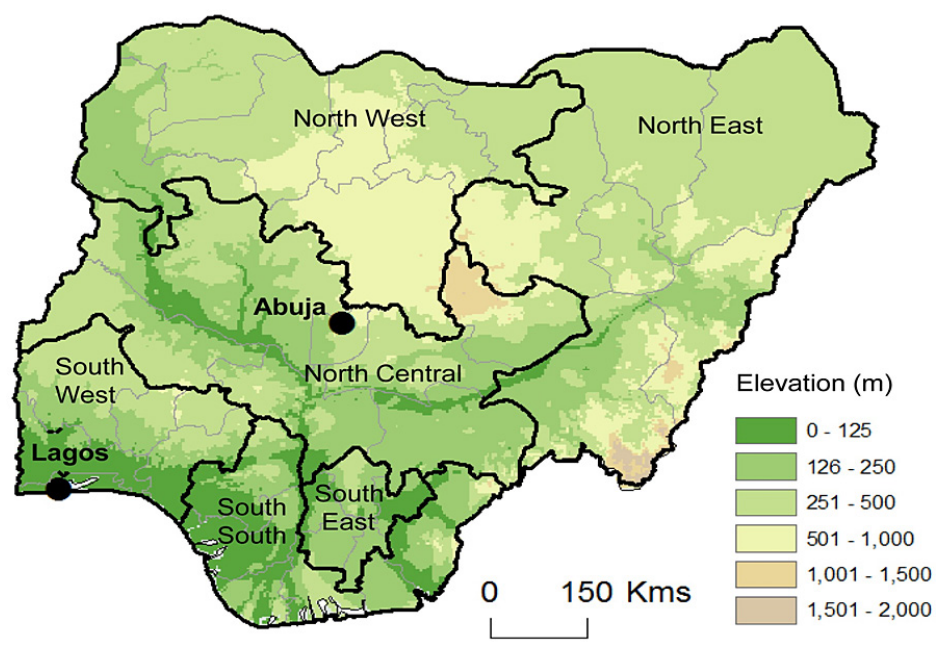

Fig.1. Map of Nigeria and its geopolitical zones. North Central; North East; North West; South East; South South; and South West

Source: Okorie, et al. ${ }^{17}$

\section{Method}

Data Source

Data utilised for this study were sourced from the ninth round of the Nigeria Demographic and Health Survey, NDHS, 2018. The NDHS was conducted between August and December 2018 by the National Population Commission (NPC) with technical support and assistance from the United States Agency for International Development (USAID) with ICF International. The 2018 NDHS was a nationwide survey conducted on women aged 15-49 years, where information about birth history and children under-five were ascertained and gathered. The 2018 NDHS utilized four (4) questionnaires: The Household Questionnaire, the Woman's Questionnaire, Man's Questionnaire, and the Biomarker Questionnaire. The questionnaires, based on the DHS Program's standard Demographic and Health Survey (DHS-7) questionnaires, were adapted to reflect the population and health issues relevant to Nigeria. In specific terms, the birth recode dataset which focussed on mothers whose children were between the ages 0-59 months to ascertain the predictive influence of the postnatal care service utilised by mothers during postnatal periods and child morbidity experience in the last five years that preceded the survey was used.

In this study, however, the birth recode dataset were extracted where individual women questionnaire was used. The women's questionnaire was used to collect information from all eligible women age 15-49. These women were asked questions on the following topics: background characteristics [including age, education, and media exposure]; birth history and child mortality; knowledge, use, 
and source of family planning methods; antenatal, delivery, and postnatal care; vaccinations and childhood illnesses [child morbidity]; breastfeeding and infant feeding practices; women's minimum dietary diversity; women's work and husbands' background characteristics, etc. However, for this study, only the socio-demographic characteristics of women, birth history, postnatal care information and child illness [child morbidity] that were extracted for the analysis in this study.

\section{Sample and Sampling Techniques}

The total number of women captured in the dataset was 127,545 of the NDHS. Of this number, a total number of 30,713 mothers whose children were under the age of five were selected as the sample size for this study. The sample for the 2018 NDHS was a stratified sample selected in two stages. In the first stage, 1,400 Enumeration Areas (EAs) were selected with probability proportional to EA size. In the second stage's selection, a fixed number of 30 households were selected in every cluster through equal probability systematic sampling, resulting in a total sample size of approximately 42,000 households. The household listing was carried out using tablets, and random selection of households was carried out through computer programming. Details of the sampling techniques can be found in the final report of 2018 NDHS.

\section{Variable Used in the Analysis The Outcome Variables}

The outcome variables of interest in this study were: (i) postnatal care services utilisation, and (ii) child morbidity experienced by mothers. The postnatal care services utilised by the respondents was measured by the place of delivery of their babies. This was captured by the facility where a respondent was delivered of a baby in the last five years that preceded the survey. These facilities were ranged from home, respondent's home, other homes, other; public sector, government hospitals, government health centre, government post, other public sectors, private sector, private hospitals/clinics to other private sectors. These facilities were further re-categorised into traditional $\{0\}$ or modern $\{1\}$. It is traditional if a respondent indicated that she was delivered of a baby either at home, respondent's home, other homes or any other place rather than a modern facility. And modern, if a respondent signified that she was delivered of a baby either in the public sector, government health centre, government health post, other public sectors, private sector, private hospitals/clinics, or any other private sector.

Child morbidity, on the other hand, was measured by the experience of any under-five disease diagnosed. These were captured by series of questions which ranged from whether children under the age of five had been diagnosed of diarrhoea recently; have had a fever in the last two weeks; have had a cough in the last two weeks; had short rapid breaths; had a problem in the chest or blocked or running nose and severe; or had mild or moderate anaemia level. The responses were all in either yes (1) or no (0). It is "yes" a respondent had experienced the disease diagnosed during the period indicated and "no" if the respondent did not have the experience of such disease of under-five in the period. Respondents' responses were further re-grouped as no child morbidity $\{0\}$ if there was no disease diagnosed with under-five children, and child morbidity $\{1\}$ if a respondent had ever had the experience of any disease.

\section{The Independent/Explanatory Variables}

The selection of the explanatory variables in this study was guided by Anderson-Newman's [14] Model of healthcare utilisation which proposed that the utilisation of any healthcare facility by an individual is determined by three factors, namely: the predisposing factors, enabling factors, and the need factor. However, only the variables related to the predisposing factors and the enabling factors were included in the analysis of this study. The predisposing factors are the socio-economic cum cultural traits of individuals that precede their health conditions and statuses such as region, age, educational level, and location. This study factored into the analysis the region of the respondent [South-West, South-East, South-South, North-West, North-East, North-Central], age, educational level [nor formal education, primary, secondary, tertiary], residence [rural/urban].

Table 1 presents the summary of the measurements and definition of both the dependent and independent variables as used in the study. 
Table 1: Measurement, definition, variables and codes

\section{Variables \\ Dependent variable:}

a) Postnatal care service utilised
Measured by the place of delivery of babies - b) Child morbidity

\begin{abstract}
Children under-five ever-diagnosed of any disease?
\end{abstract}

\section{Main Independent variables:}

Region

PNC service utilization
The six geopolitical zones in Nigeria represent the regions

Place of delivery of respondents' babies

\section{Socio-demographics variables:}

Age in the Age in years 5-year group

Residence Place of residence

Educational level

Highest educational No formal education, Primary, attainment
Traditional \{home, respondent home, other homes, other\}

Modern \{public sector, government hospitals, government health centre, government health post, other public sectors, private sector, private hospitals/clinics, other private sectors\}

\section{Not diagnosed of any disease}

Diagnosed of any disease \{had diarrhoea recently, had a fever in the last two weeks, had a cough in last two weeks, short rapid breaths, a problem in the chest or blocked or running nose and severe, mild or moderate anaemia level\}

South West, South-South, South East, North Central, North East and North West

Traditional \{home, respondent's home, other homes, other\}

Modern \{public sector, government hospital, government health centre, government health post, other public sectors, private sector, private hospital/clinic, other private sectors\}

$15-19 ; 20-24 ; 25-29 ; 30-34$ $35-39 ; 40-44 ; 45-49$

Urban, rural Secondary, Tertiary \{any school attended other than primary and secondary\}

\section{Code}

$0=$ Traditional

1= Modern

$0=$ No child morbidity

1 = Child morbidity
$1=$ South West

2 = South South

3 = South East

$4=$ North Central

$5=$ North East

$6=$ North West

$0=$ Traditional

\section{$1=$ Modern}




\begin{tabular}{|c|c|c|c|}
\hline Religion & $\begin{array}{l}\text { Membership of any } \\
\text { religious groups }\end{array}$ & $\begin{array}{l}\text { Catholic, Other Christians, } \\
\text { Islam, Traditionalist }\end{array}$ & $\begin{array}{l}1=\text { Catholic } \\
2=\text { Other Christians } \\
3=\text { Islam } \\
4=\text { Traditionalist }\end{array}$ \\
\hline Ethnicity & $\begin{array}{l}\text { Membership of the } \\
\text { major and minority } \\
\text { ethnic group }\end{array}$ & $\begin{array}{l}\text { Yoruba, Igbo, Hausa, The Minority } \\
\{\text { ljaw, Kanuri, Tiv, Igala, Kalabari, etc. }\}\end{array}$ & $\begin{array}{l}1=\text { Yoruba; } 2=\text { Igbo } \\
3=\text { Hausa; } \\
4=\text { The Minority }\end{array}$ \\
\hline Number of children & $\begin{array}{l}\text { Number of children } \\
\text { ever-born by the } \\
\text { respondents }\end{array}$ & $\begin{array}{l}\text { Measured at continuous but regroup } \\
\text { as } 0-3 \text { children; } 4-6 \text { children; } 7+ \\
\text { children }\end{array}$ & $\begin{array}{l}1=0-3 ; 2=4-6 \\
3=7+\end{array}$ \\
\hline
\end{tabular}

This study also factored in the ethnicity [Yoruba, Igbo, Hausa, The Minority] of the respondent, the number of children-born [0-3, 4-6, 7+] as the enabling factors for PNC services utilization and child morbidity; while the need factor is the most immediate cause of health care service utilisation. Within the context of this study, the term "traditional" refers to cultural activities found in in various regions in Nigeria used as a postnatal activity by women. Examples include, the use of traditional birth attendants, use of bone setters, use of traditional herbs, etc. In other words, they are healthcare delivery practices channels through which women (or her family members) use in seeking medical attention for children below the ages of 5 by recourse to indigenous knowledge and experiences. "Modern" postnatal healthcare services on the other hand refers to all orthodox or conventional medical practices used by women (or their family members) to improve under-five health status.

\section{Data Management and Analysis}

After the extraction of relevant variables suitable for the analysis of this study as described in Table 1, the data were further cleaned and recoded for appropriate statistical analysis. However, both univariate, bivariate and multivariate statistical tools were used. With the aid of the Statistical Package for Social Sciences (SPSS version 21), descriptive and chi-square test were used to analyse the sociodemographic profiles of the respondents as well as the PNC services utilisation. To predict the likelihood of child morbidity, logistic regression was used to analyse and predict the likelihood of the regions and PNC service utilisation [traditional or modern health care facilities] on child morbidity experienced by women immediately after delivery as well as determining the predictive influence of mothers' socio-demographic variables on child morbidity (whether a child under the age of five developed any health condition or not).

\section{Ethical Considerations}

Ethical approval was sought from the DHS Program archivist, and the permission to download the dataset was granted on the $7^{\text {th }}$ November 2019 via https://www.dhsprogram.com/data/dataset_admin/ login_main.cfm. All ethical standards prescribed by DHS in the use of the dataset were strictly applied in this study.

\section{Results}

\section{Socio-Demographic Characteristics of the Respondents}

From Table 2 which presents the socio-demographic characteristics of the respondents, the Northern part of the country generally have the highest numbers of sampled respondents with the North-West having the highest proportion of the respondents $(29.1 \%)$, followed by those in North-East (21.1\%), and NorthCentral $(17.6 \%)$. In the Southern region which is made of the South-East, South-West and SouthSouth, the South-East have the highest proportion of the respondents (11.5\%).

The age distribution of the respondents indicated that the mean age of the respondents was $29.54 \pm 6.77$. Nonetheless, those between $25-29$ years formed the highest category of the sampled population, while $45-49$ years categories had the least proportion $(2.5 \%)$. The residential location of the respondents shows that more than half of the respondents $(64.7 \%)$ resided in rural areas. The educational level distribution also revealed that close to half of the participants $(44 \%)$ had no formal education, while only about 8 percent had tertiary education. 
Furthermore, the report shows that more than half of the sampled participants were associated with the Islamic religion $(59.0 \%)$, while only approximately 1 percent of the participants indicated that they were traditionalist. More so, the ethnic composition of the respondents revealed that Hausa is the major ethnic group, followed by other minority ethnic groups such as; Tiv, ljaw, Urhobo, Igala, Nupe and Kanuri among others. Yoruba on the other hand, was the least sampled ethnic group (9.9\%) among the three major ethnic groups in the study. Finally, the sociodemographic profiles of the respondents indicated that those who had between $0-3$ children formed the highest proportion of respondents sampled for the study $(47 \%)$.

Table 2: Distribution of respondents by socio-demographic characteristics

\begin{tabular}{|c|c|c|}
\hline Demographic variables & Frequency $(n=30713)$ & Percentage (\%) \\
\hline \multicolumn{3}{|l|}{ Region } \\
\hline North-Central & 5403 & 17.6 \\
\hline North-East & 6481 & 21.1 \\
\hline North-West & 8934 & 29.1 \\
\hline South-East & 3545 & 11.5 \\
\hline South-South & 3021 & 9.8 \\
\hline South-West & 3329 & 10.8 \\
\hline \multicolumn{3}{|l|}{ Age $($ Mean=29.54 \pm 6.77$)$} \\
\hline $15-19$ & 1286 & 4.2 \\
\hline $20-24$ & 5960 & 19.4 \\
\hline $25-29$ & 8660 & 28.2 \\
\hline $30-34$ & 6963 & 22.7 \\
\hline $35-39$ & 4915 & 16 \\
\hline $40-44$ & 2171 & 7.1 \\
\hline $45-49$ & 758 & 2.5 \\
\hline \multicolumn{3}{|l|}{ Residence } \\
\hline Urban & 10851 & 35.3 \\
\hline Rural & 19862 & 64.7 \\
\hline \multicolumn{3}{|l|}{ b } \\
\hline No education & 13527 & 44 \\
\hline Primary & 4776 & 15.6 \\
\hline Secondary & 9913 & 32.3 \\
\hline Tertiary & 2497 & 8.1 \\
\hline \multicolumn{3}{|l|}{ Religion } \\
\hline Catholic & 2744 & 8.9 \\
\hline Other Christian & 9594 & 31.2 \\
\hline Islam & 18113 & 59 \\
\hline Traditionalist & 262 & 0.9 \\
\hline \multicolumn{3}{|l|}{ Ethnicity } \\
\hline Yoruba & 3037 & 9.9 \\
\hline Igbo & 4200 & 13.7 \\
\hline Hausa & 12460 & 40.6 \\
\hline The Minorities & 11016 & 35.9 \\
\hline \multicolumn{3}{|c|}{ Number of children ever-born } \\
\hline $0-3$ & 14434 & 47 \\
\hline $4-6$ & 10696 & 34.8 \\
\hline $7+$ & 5583 & 18.2 \\
\hline
\end{tabular}


Regional differences in PNC Services Utilisation in Nigeria

Table 3 simultaneously examines the distribution of respondents by PNC services utilised and their regions while also exploring the association between regions, socio-demographic characteristics and PNC services utilised (traditional or modern). It was reported that about two-fifth of those in the North West utilised traditional PNC services (being the highest), while those in the southeast has the highest proportion of women using modern health care facilities for PNC services. It was also found that there is a statistically significant relationship between region and $P N C$ services utilisation $\left(x^{2}=7411.046, D F=5, p<0.05\right)$.

Table 3: Association between Regions, socio-demographic characteristics and PNC services utilisation in Nigeria

\begin{tabular}{|c|c|c|c|}
\hline \multirow[t]{2}{*}{ Variables } & \multicolumn{2}{|c|}{ PNC Services Utilisation $(n=30,713)$} & \multirow{2}{*}{$\begin{array}{c}\text { Chi-square } \\
\text { DF } \\
\text { p-value }\end{array}$} \\
\hline & Modern (\%) & Traditional (\%) & \\
\hline \multicolumn{4}{|l|}{ Region } \\
\hline South West & $2528(20.3)$ & $801(4.4)$ & \\
\hline South-South & $1362(10.9)$ & $1659(9.1)$ & $x^{2}=7411.046$ \\
\hline South East & $2865(23.0)$ & $680(3.7)$ & $D F=5$ \\
\hline North Central & $2746(22.0)$ & $2657(14.6)$ & $P=0.000$ \\
\hline North East & $1621(13.0)$ & $4860(26.6)$ & \\
\hline North West & 1354 (10.9) & $7580(41.6)$ & \\
\hline \multicolumn{4}{|l|}{ Age } \\
\hline $15-19$ & $391(3.1)$ & 895 (4.9) & \\
\hline $20-24$ & $2102(16.8)$ & $3858(21.2)$ & \\
\hline $25-29$ & 3609 (28.9) & $5051(27.7)$ & $x^{2}=211.851$ \\
\hline $30-34$ & $3102(24.2)$ & $3861(21.2)$ & $\mathrm{DF}=6$ \\
\hline $35-39$ & $2163(17.3)$ & $2752(15.1)$ & $P=0.000$ \\
\hline $40-44$ & $846(6.8)$ & $1325(7.3)$ & \\
\hline $45-49$ & $263(2.1)$ & $495(2.7)$ & \\
\hline Residence & & & $x^{2}=2938.521$ \\
\hline Urban 6638 (53.2) & $4213(23.1)$ & $D F=1$ & \\
\hline Rural 5838 (46.8) & $14024(76.9)$ & $P=0.000$ & \\
\hline \multicolumn{4}{|l|}{ Education } \\
\hline No education & $1939(15.5)$ & $11588(63.5)$ & $x^{2}=8427.927$ \\
\hline Primary & $1992(16.0)$ & $2784(15.3)$ & $D F=3$ \\
\hline Secondary & $6361(51.0)$ & 3552 (19.5) & $P=0.000$ \\
\hline Tertiary & $2184(17.5)$ & $313(1.7)$ & \\
\hline \multicolumn{4}{|l|}{ Religion } \\
\hline Catholic & $1968(15.8)$ & $776(4.3)$ & $x^{2}=4486.880$ \\
\hline Other Christians & $5837(46.8)$ & 3757 (20.6) & $D F=3$ \\
\hline Islam 4609 (36.9) & $13504(74.0)$ & $P=0.000$ & \\
\hline Traditionalist & $62(0.5)$ & $200(1.1)$ & \\
\hline \multicolumn{4}{|l|}{ Ethnicity } \\
\hline Yoruba & 2314 (18.5) & $723(4.0)$ & $x^{2}=7265.647$ \\
\hline Igbo $3402(27.3)$ & $798(4.4)$ & $\mathrm{DF}=3$ & \\
\hline Hausa 2147 (17.2) & $10313(56.5)$ & $P=0.000$ & \\
\hline The Minorities & $4613(37.0)$ & $6403(35.1)$ & \\
\hline \multicolumn{4}{|l|}{ Number of children } \\
\hline $0-3$ children & $7129(57.1)$ & $7305(40.1)$ & $x^{2}=1293.965$ \\
\hline $4-6$ children & $4127(33.1)$ & $6569(36.0)$ & $\mathrm{DF}=2$ \\
\hline $7+$ children & $1220(9.8)$ & 4363 (23.9) & $P=0.000$ \\
\hline
\end{tabular}

Significant at $p<0.05^{*}$ 
Further analysis of the relationship between socio-demographic characteristics and PNC services utilisation shows that there is a statistically significant relationship between age $\left(x^{2}=211.851\right.$, $D F=6, p<0.05)$, residence $\left(x^{2}=2938.521, D F=1\right.$, $p<0.05)$, education $\left(x^{2}=8427.93, D F=3, p<0.05\right)$, religion $\left(x^{2}=4486.880, D F=3, p<0.05\right)$, ethnicity $\left(x^{2}=7265.647, D F=3, p<0.05\right)$, number of children $\left(x^{2}=1293.965, D F=2, p<0.05\right)$ and PNC service utilisation.

It also means that there are significant differences in the use of either modern or traditional PNC service utilisation across the categories of sociodemographic characteristics of the respondents.
Association between Regions, PNC Service Utilisation and Child Morbidity in Nigeria

Figure 1 first reports the percentage distribution of the respondents by the occurrence of child morbidity in Nigeria. It was reported that nearly half of children under the age of five experienced child morbidity in the overall, while those in the North West had the highest percentage of the prevalence of morbidity in the country, which was closely followed by those in the North East and North Central with those in the South West having the lowest percentage. This implies that there is a high prevalence of child morbidity in the Northern part of Nigeria when compared to those in the Southern part of the country.

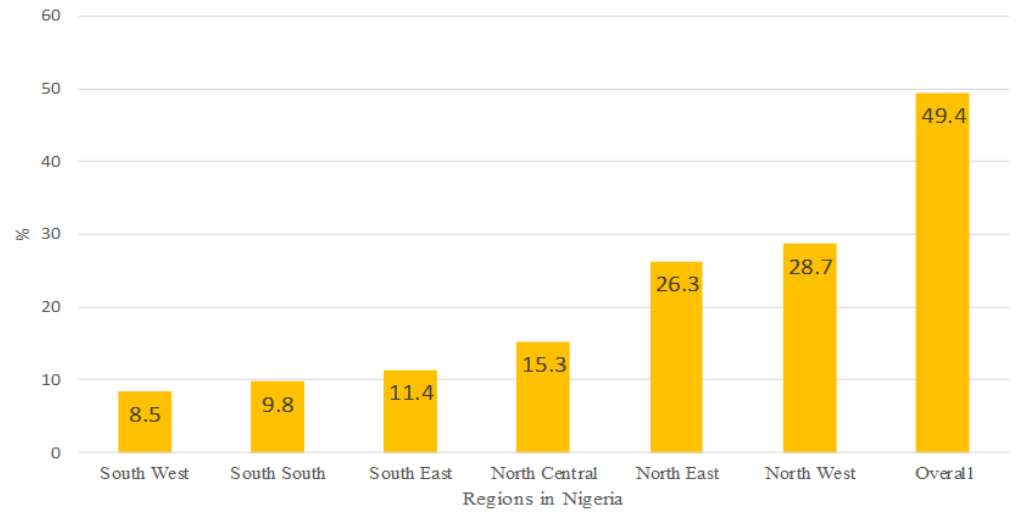

Fig. 1: Percentage distribution of child morbidity by regions in Nigeria

To determine the predictive influence of regions and PNC service utilised by women of reproductive age on child morbidity, table 4 presents the results of the logistic regression at two models. While the first model was used to explore the predictive influence of regions and PNC utilised on child morbidity, model 2 included socio-demographic variables of the respondents as confounders to examine the net effects of the variables on child morbidity.

In the first model, however, there is a statistically significant association between the region and the type of PNC service utilised by women on child morbidity. The odds of those who were in the SouthSouth $(\mathrm{OR}=1.46,95 \%$ Confidence Interval $[\mathrm{Cl}]=$ $1.316-1.611 ; p=0.01)$, South East $(O R=1.50,95 \%$ Confidence Interval $[\mathrm{Cl}]=1.365-1.654 ; \mathrm{p}=0.01$ ), North Central $(\mathrm{OR}=1.13,95 \%$ Confidence Interval $[C l]=1.033-1.235 ; p=0.05)$, North East $(O R=2.31$, $95 \%$ Confidence Interval $[\mathrm{Cl}]=2.107-2.521 ; p$
$=0.01)$ and North West $(\mathrm{OR}=1.35,95 \%$ Confidence Interval $[\mathrm{Cl}]=1.233-1.468 ; \mathrm{p}=0.01$ ) are far above those in the South West region. Those in the North East have the highest odds of child morbidity than oLther regions.

This shows that there are variations in the prevalence of child morbidity across the regions in Nigeria with the North East having the highest odds. In the same vein, those who resided in the rural areas at the time of the survey are observed to be 1.2 times more likely to experience child morbidity than those in the urban centre. This suggests that the place of residence of the respondents can have a significant influence on child morbidity.

In the second model when the socio-demographic variables of the respondents were factored into the analysis, the statistical significance influence of the region on child morbidity persisted though 
with a drop in the propensity especially with those in North Central and North West which had no statistically significant influence on child morbidity. On the rural-urban dichotomy, although statistically significantly associated with child morbidity, there is a drop compared to the first model when sociodemographic characteristics of the respondents were not included in the model.

Table 4: Logistic regression analysis predicting child morbidity from regions, PNC facilities utilised and socio-demographic variables of the respondents in Nigeria

\begin{tabular}{|c|c|c|c|c|}
\hline \multirow[t]{2}{*}{ Variables } & \multicolumn{2}{|c|}{ Child morbidity (column \%) } & \multirow{2}{*}{$\frac{\text { Model } 1}{\text { OR }[95 \% \mathrm{Cl} \text { for } \operatorname{Exp}(\mathrm{B})}$} & \multirow{2}{*}{$\frac{\text { Model } 2}{\text { AOR }[95 \% \text { Cl for } \operatorname{Exp}(B)}$} \\
\hline & NO (\%) & YES (\%) & & \\
\hline \multicolumn{5}{|l|}{ Region } \\
\hline South West (RC) & $2033(13.1)$ & $1296(8.5)$ & - & - \\
\hline South-South & $1529(9.8)$ & $1492(9.8)$ & $1.456^{* *}[1.316-1.611]$ & $1.352^{* *}[1.178-1.552]$ \\
\hline South East & $1818(11.7)$ & $1727(11.4)$ & $1.503^{* *}[1.365-1.654]$ & $1.303^{*}[1.093-1.552]$ \\
\hline North Central & 3087 (19.8) & $2316(15.3)$ & $1.130 *[1.033-1.235]$ & $.976[.862-1.105]$ \\
\hline North East & $2498(16.1)$ & $3983(26.3)$ & $2.305^{\star *}[2.107-2.521]$ & $1.835^{* *}[1.603-2.100]$ \\
\hline North West & $4590(29.5)$ & $4344(28.7)$ & $1.345^{\star *}[1.233-1.468]$ & $1.013[.880-1.165]$ \\
\hline \multicolumn{5}{|c|}{ PNC Service Utilized } \\
\hline Modern (RC) & $6816(43.8)$ & $5660(37.3)$ & - & - \\
\hline Traditional & $8739(56.2)$ & $9498(62.7)$ & $1.177^{* *}[1.116-1.241]$ & $1.079 *[1.018-1.142]$ \\
\hline \multicolumn{5}{|l|}{ Age } \\
\hline $15-19(\mathrm{RC})$ & $594(3.8)$ & $692(4.6)$ & & - \\
\hline $20-24$ & 2945 (18.9) & $3015(19.9)$ & & $.908[.804-1.027]$ \\
\hline $25-29$ & 4407 (28.3) & $4253(28.1)$ & & $.875^{*}[.773-.990]$ \\
\hline $30-34$ & $3596(23.1)$ & $3367(22.2)$ & & $.832^{*}[.729-.948]$ \\
\hline $35-39$ & $2495(16.0)$ & $2420(16.0)$ & & $.823^{*}[.715-.948]$ \\
\hline $40-44$ & $1133(7.3)$ & $1038(6.8)$ & & $.716^{* *}[.612-.839]$ \\
\hline $45-49$ & $385(7.3)$ & $373(2.5)$ & & $.738^{*}[.605-.899]$ \\
\hline \multicolumn{5}{|l|}{ Residence } \\
\hline Urban (RC) & 5965 (38.3) & $4886(32.2)$ & & - \\
\hline Rural & $9590(61.7)$ & $10272(67.8)$ & & $1.140^{* *}[1.079-1.203]$ \\
\hline \multicolumn{5}{|l|}{ Education } \\
\hline No education (RC) & 6445 (41.4) & $7082(46.7)$ & & - \\
\hline Primary & $2290(14.7)$ & $2486(16.4)$ & & $1.144^{* *}[1.063-1.231]$ \\
\hline Secondary & $5282(34.0)$ & 4631 (30.6) & & $1.007[.937-1.083]$ \\
\hline Tertiary & $1538(9.9)$ & $959(6.3)$ & & $.807^{* *}[.725-.899]$ \\
\hline \multicolumn{5}{|l|}{ Religion } \\
\hline Catholic (RC) & $1498(9.6)$ & $1246(8.2)$ & & - \\
\hline Other Christians & $5095(32.8)$ & $4499(29.7)$ & & $1.088[.993-1.192]$ \\
\hline Islam & $8795(56.5)$ & $9318(61.5)$ & & $1.115^{\star}[1.000-1.243]$ \\
\hline Traditionalist & $167(1.1)$ & $95(0.6)$ & & $.635^{*}[.485-.832]$ \\
\hline \multicolumn{5}{|l|}{ Ethnicity } \\
\hline Yoruba (RC) & $1882(12.1)$ & $1155(7.6)$ & & - \\
\hline lgbo & $2185(14.0)$ & $2015(13.3)$ & & $1.200^{*}[1.007-1.429]$ \\
\hline Hausa & $5937(38.2)$ & $6523(43.0)$ & & $1.243^{*}[1.080-1.430]$ \\
\hline The Minorities & $5551(35.7)$ & $5465(36.1)$ & & $1.093[.962-1.241]$ \\
\hline \multicolumn{5}{|c|}{ Number of children } \\
\hline $0-3$ children (RC) & $7558(48.6)$ & $6876(45.4)$ & & - \\
\hline $4-6$ children & $5414(34.8)$ & $5382(34.8)$ & & $1.066^{*}[1.003-1.133]$ \\
\hline $7+$ children & $2583(16.6)$ & $3000(19.8)$ & & $1.260^{* *}[1.151-1.379]$ \\
\hline Chi-Square & & & 659.172 & 169.363 \\
\hline Degree of freedom & & & 6 & 18 \\
\hline
\end{tabular}


-2Log likelihood

Cox \& Snell R Square

Nagelkerke R Square

\author{
41912.955 \\ 0.021 \\ .028
}

41743.592
0.027
.035

Significant at $p<0.01^{* *}$ or $p<0.05^{*} ; \mathrm{RC}=$ Reference Category; $\mathrm{PNC}=$ Postnatal Care; $\mathrm{OR}=$ Odds Ratio; $\mathrm{AOR}=$ Adjusted Odds Ratio; Number of Observation $=30,713$

Further analysis revealed that the age of the respondents is statistically associated with child morbidity. Those who are in the age categories of 25 and above are found to be less likely to experience child morbidity than those between 15-19 years. This may be largely due to the fact that as the mother advance in age, the management of underfive children relative to morbidity increases with age which those in the lower categories of age may not have the capacity.

Relative to the influence of residence on child morbidity, there is a statistically significant association between residence and child morbidity. Those who resided in the rural areas of Nigeria are 1.14 times more likely to experience child morbidity than those in the urban centre. The education of the respondents is indeed fundamental to child morbidity. While those who had attained primary educational level are 1.14 times more likely to experience child morbidity than those who did not attend any formal education, those with tertiary educational level are $19.3 \%$ less likely to experience child morbidity than those without any formal education.

Religion was also found to be critical among the study population on child morbidity. Those who adherents of Islam are 1.11 times more likely to experience child morbidity than those who were followers of Catholic, while the traditionalists were $36.5 \%$ less likely to experience child morbidity when compared to those in the reference category. It then means that the risk of child morbidity is higher among the followers of Islamic religion than those in other categories of religion.

Ethnicity and child morbidity are also statistically significantly related. Those who are Igbo and Hausa, in particular, are $20 \%$ and $24.3 \%$ more likely to experience child morbidity than those in Yoruba. Although there is no statistically significant association between those in the minorities and child morbidity in Nigeria, yet variations existed in the experience of child morbidity in the country.
On the account of the number of children a respondent has, there is a statistically significant association between those who had between four and six children, seven children and above and child morbidity in the country. For example, those who had between $4-6$ children and $7+$ children are $6.6 \%$ and $26 \%$ more likely to experience child morbidity than those who had between zero and three children. This suggests that as the number of children increases, the more likely a woman exposes to the risk of child morbidity in the country.

\section{Discussion}

The study found that North West region has the highest proportion of respondents, followed by those in North East, and North Central with those in the South-South having the least proportion in the country. This simply suggests that women of reproductive age sampled by the NDHS in the northern part of Nigeria were far higher than those in the southern regions. This study also indicated that the average age of women sampled in the study was 30 years. This is by implication suggesting that majority of those who were captured in the survey were young women who were also reproductively active enough to have children and may require postnatal care services.

Findings also indicated that majority of the respondents resided in rural areas while only a few of the respondents were urban residents. This simply means that there are more rural areas in the country than the urban centres which may inform the nature of postnatal care facilities that will be available for the teeming population of mothers in the country. Findings on the educational attainment of the respondents showed that almost half of them did not have formal education, while the highest proportion of the respondents that had attended formal education was those who had secondary school certificate compared to just one in ten who had tertiary educational attainment. This further explains the fact that the majority of the women in the survey were not residing in the urban centres 
where there are diverse opportunities to attain higher educational level than the rural areas.

Earlier studies have shown that there are variations in the use of PNC services by regions12 based on sociocultural differences and some factors affecting PNC service utilization in some facilities. ${ }^{4.11 .15}$ This study also found that PNC services utilization varied significantly by regions and socio-demographic characteristics with those in the North East and North West using more of the traditional facilities than the modern health care facilities for PNC services. These variations could be attributed to some forms of barriers identified by Ugboanusi and colleagues 4 such as transportation and differences in wealth quintiles. Takai et al. ${ }^{16}$ had also earlier identified socio-demographic factors such as awareness, educational status, marital status, and husband's educational status as determinants of the underutilisation of modern PNC services in the NorthEastern part of the country. Somefun and Ibisomi ${ }^{15}$ on their own part identified these factors to include distance, cost and availability of health facilities. These factors the added leave mothers with no option than resorting to traditional medical practices.

Findings revealed that there is significant variation in the likelihood of child morbidity by regions in Nigeria. While the findings indicated that those in the SouthSouth, South East, North Central and North West are $1.5,1.5,1.3$ and 1.3 times more likely to experience child morbidity than those in the South West region respectively, mothers in the North East are two times more likely to experience child morbidity than those in the South West.

It was also revealed that the socio-demographic characteristics of the respondents predicted child morbidity in Nigeria. This finding corroborates the work of Sotunsa et al. ${ }^{7}$ who found that there is a significant relationship between postnatal care utilisation and maternal and child mortality in a population. Anderson-Newman Model ${ }^{14}$ further substantiate this position when it stated that sociodemographic factors are the predisposing factors of health condition that influence the use of PNC service utilisation.

Previous studies using the 2013 NDHS also established an association between ethnicity and maternal/child health in Nigeria. For instance,
Ononokpono et al., ${ }^{18}$ study found that ethnic diversity was significantly related to the use of a health facility for childbirth. In establishing the reason for the differences in the use of health facilities between ethnic groups in Nigeria, Ononokpono et al., ${ }^{18}$ stated that the likelihood of health facility birthing was higher among women in high ethnically diverse (heterogeneous) and mixed communities (as found in the north-central and south-south regions of Nigeria) than in women residing in ethnically homogeneous communities (as can be found in the South-west, South-east and Northwest)..$^{18-19}$

This is because women in these heterogeneous settings have a high-level social network, which could support increased information sharing about maternal health care services and the use of such services, ${ }^{20}$ which could influence the use of maternal health care services. Another plausible explanation could be that women residing in communities with a high proportion of women from different ethnic groups or heterogeneous communities may be more exposed to the health care practices of different ethnic groups, which could become a general norm and consequently influence the use of a health facility for birthing.

On the other hand, homogenous regions which are predominantly Hausa/Fulani, Igbo, and Yoruba low use of health facilities for childbirth among women have been attributed to a common cultural practices and traditions that could influence health care behavior. ${ }^{21}$ Nevertheless, this finding contrasts with those in some other climes in Africa. For instance, in Uganda and other places, findings suggest that high ethnically diverse districts tend to be associated with poor health outcomes or, in most cases, are not significantly related to health decisions. ${ }^{22-23}$

\section{Conclusion}

Following the logic of this research, it can be deduced that the occurrence of any disease in Nigeria population among the children under the age of five varied significantly by regions as well as the nature of PNC service utilised. Although other variables such as the socio-demographic characteristics of the respondents influenced the variation to some extent, it is quite observable that the variations that existed in PNC service utilisation by regions have greatly influenced the disparities in the prevalence of 
child morbidity across the regions in the country. As such, there should be region-specific programmes of action that will facilitate the use of modern PNC service utilisation across all the regions.

Given the findings of the study, the following are recommended for the health policymakers to take action

- There should region-specific sensitisation of women on the need for the use of modern health care for both antenatal care and postnatal care services to reduce the high prevalence of child morbidity across the regions.

- Women should reframe from delivering at homes or non-health care designated centres

- The government and other stakeholders in the health sector should assist the provision of adequate modern health care facilities across the regions while laying more emphasis on maternal and child health care facilities.

- The provision of Primary Health Care (PHC) facilities should be encouraged in all communities as this remains the closest health care facilities for easy accessibility for mother and children to combat child morbidity that informed child deaths.

\section{Acknowledgements}

The authors wish to appreciate the Demographic and Health Survey Program for their support in allowing us to have free access to download the original dataset of the NDHS.

\section{Funding}

The authors have no support or funding to report.

\section{Conflict of Interest}

The authors declare that they have no competing interests.

\section{References}

1. World Health Organization. WHO recommendations on postnatal care of the mother and newborn. World Health Organization, 2014.

2. National Population Commission (NPC) and ICF. Nigeria Demographic and Health Survey 2018. Abuja, Nigeria, and Rockville, Maryland, USA: NPC and ICF, 2019.

3. Ugboaja JO, Berthrand NO, Igwegbe AO, ObiNwosu, AL. Barriers to postnatal care and exclusive breastfeeding among urban women in southeastern Nigeria. Nigerian medical journal: journal of the Nigeria Medical Association 2013;54(1):45.

4. Ugboanusi CJC, Sabitu K, Gobir AA, Nmadu AG, Joshua IA. Factors Affecting the Utilization of Postnatal Care Services in Primary Health Care Facilities in Urban and Rural Settlements in Kaduna State, North-western Nigeria. American Journal of Public Health 2019;7(3): 111-117.

5. Olajubu AO, Olowokere AE, Ogundipe MJ, Olajubu TO. Predictors of Postnatal Care Services Utilization Among Women in Nigeria: A Facility-Based Study. Journal of Nursing Scholarship 2019;51(4):408-416.

6. Munnaya P, Durrant K, Fisher J, Cherisich M,
Luchters S. (2015). Attitudes and behaviours of maternal health care providers in interactions with clients: a systemic review. Globalization and health 2015;11(1):36.

7. Sotunsa JO, Adeniyi AA, Imaralu JO, Fawole B, Adegbola O, Aimakhu CO, ... Oladapo OT. Maternal near-miss and death among women with postpartum haemorrhage: a secondary analysis of the Nigeria Near-miss and Maternal Death Survey. BJOG: An International Journal of Obstetrics \& Gynaecology 2019;126 (Suppl 3):19-25.

8. Abebe Z, Tariku A, Bikes GA, Wassie MM, Gonete KA, Awoke T, ... Alemu K. Poor child complementary Feeding Practices in northwest Ethiopia: Finding from the Baseline Survey of Nutrition Project, 2016. Italian Journal of Pediatrics 2019; 45(1):154.

9. Agho KE, Ezeh OK, Issaka Al, Enoma Al, Baines $S$, Renzaho AMN. Population attributable risk estimates for factors associated with non-use of postnatal care services among women in Nigeria. BMJ open 2016; 6(7): e010493.

10. United Nations -Inter-Agency Group for Child Mortality Estimation, UN-IGME. Levels and trends in child mortality, 2019. Retrieved from: https://www.unicef.org/media/60561/file/UN- 
IGME-child-mortality-report-2019.pdf

11. Rao PN, Udani R, Nanavati R. Kangaroo mother care for low birth weight infants: a randomized controlled trial. Indian Pediatr 2008; 45:17-23

12. Defar A, Okwaraji YB, Tigabu Z, Persson LA, Alemu K. Geographic differences in maternal and child health care utilization in four Ethiopian regions; a cross-sectional study. International journal for equity in health 2019;18(1):173.

13. Assembly UG. Transforming our world: the 2030 agenda for sustainable development, resolution adopted by the General Assembly. A/70/L. 1. New York: UN General Assembly, 2015.

14. Andersen RM. Revisiting the behavioral model and access to medical care: Does it matter? J Health Soc Behav.1995; 36: 1-10.

15. Somefun OD, Ibisomi L. Determinants of postnatal care non-utilization among women in Nigeria. BMC research notes, 2016; 9(1): 21.

16. Takai IU, Dlakwa HD, Bukar M, Audu BM, Kwayabura AS. Factors responsible for under-utilization of postnatal care services in Maiduguri, north-eastern Nigeria. Sahel Medical Journal 2015;18(3):109.

17. Okorie P.N, Ademowo GO, Saka Y, Davies E, Okoronkwo C, Bockarie MJ, Molyneux DH, Kelly-Hope LA. Lymphatic Filariasis in Nigeria; Micro-stratification Overlap Mapping (MOM) as a prerequisite for cost-effective resource utilization in control and surveillance. PLOS
Negl Trop Dis 2013; 7(9): e2416. doi:10.1371/ journal.pntd.0002416

18. Ononokpono DN, Odimegwu, CO,Adedini, SA, Imasiku ENS. Ethnic diversity and maternal health care in Nigeria. Women's Reproductive Health 2016; 3(1): 45-59. 10.1080/23293691.2016.1150701

19. Adedini AS, Odimegwu C, Imasiku ENS, Ononokpono DN, Ibisomi L. Regional variations in infant and child mortality in Nigeria: A multilevel analysis. Journal of Biosocial Science 2014; 10, 1-23. doi:10.1080/135578 58.2014.890599

20. Brockerhoff M, Hewett P. Ethnicity and child mortality in sub-Saharan Africa. Working Paper No. 107. New York, NY: Policy Research Division, Population Council, 1998.

21. Ononokpono DN, Odimegwu CO. Determinants of maternal health care utilization in Nigeria: A multilevel approach. Pan African Medical Journal 2014; 17(Supplement 1), 2.

22. Boco AG. Individual and community level effects on child mortality: An analysis of 28 demographic and health surveys in subSaharan Africa. DHS Working Paper No. 73. 2011; Calverton, MD.

23. Platas MR. Africa's health tragedy? Ethnic diversity and health outcomes. Working Group on African Political Economy 2010; California: Stanford University. 